\title{
Cancers in the Elderly Seen in Anatomical Pathology Laboratory in Lomé, Togo
}

\author{
Tchin Darré ${ }^{*}$, Atchi Walla², Tchilabalo Matchonna Kpatcha3 ${ }^{3}$, Abdoul-Samadou Aboubakari", \\ Nidain Maneh" ${ }^{5}$, Mikotakatola Koulinga' ${ }^{1}$, Koffi Amégbor ${ }^{1}$, Gado Napo Koura ${ }^{1}$ \\ ${ }^{1}$ Department of Pathology, The University Teaching Hospital of Lomé, Lomé, Togo \\ ${ }^{2}$ Department of Trauma and Orthopedic, The University Teaching Hospital of Lomé, Lomé, Togo \\ ${ }^{3}$ Department of Urology, The University Teaching Hospital of Lomé, Lomé, Togo \\ ${ }^{4}$ Department Obstetrics and Gynecology, The University Teaching Hospital of Kara, Kara, Togo \\ ${ }^{5}$ Department of Ophthalmology, The University Teaching Hospital of Lomé, Lomé, Togo \\ Email: "paolodarre@yahoo.fr
}

Received 10 December 2015; accepted 18 January 2016; published 22 January 2016

Copyright (C) 2016 by authors and Scientific Research Publishing Inc.

This work is licensed under the Creative Commons Attribution International License (CC BY). http://creativecommons.org/licenses/by/4.0/

(c) (i) Open Access

\begin{abstract}
Background: The elderly cancers are worldwide a major public health issue. Their exact incidence is unknown in Togo. The purpose of this study was to describe epidemiological and histological data of cancers in the elderly in Togo. Materials and Methods: This was a cross-sectional and descriptive study of cases of elderly cancers diagnosed at the laboratory of pathology of the university teaching hospital of Lomé from 1995 to 2014 (20 years). Cases of examination on samples of the elderly (biopsy, excision, surgical specimens) were collected from the data records of that laboratory. Results: Overall, 792/5200 cases of elderly cancer were collected representing $15.2 \%$ of all cancers diagnosed in the laboratory. The annual incidence was 39.6 cases. Patient age ranged from 65 to 103 years old, with a mean of $68.5 \pm 4$ years old. The sex ratio (M/F) was 1.3. At pathological level, the study material included pieces $(n=290$ cases; $36.6 \%)$ and biopsies $(n=502$ cases; $63.4 \%$ ). Cancers located preferably in prostate in men $(38 \%)$, and in women the most frequent locations were cervix $(16.2 \%)$ and breast $(15.8 \%)$. We noticed four histological groups: carcinomas $(n=706$ cases; $89.1 \%)$, sarcomas $(n=43$ cases; $5.5 \%)$, lymphoma $(n=34$ cases; $4.3 \%)$ and melanoma ( $\mathrm{n}=9$ cases; $1.1 \%)$. Carcinomas were dominated by adenocarcinomas $(50.1 \%)$ and squamous cell carcinomas (33.8\%); Kaposi's sarcoma (32.6\%) was the most common histological type in sarcomas. Conclusion: Our results showed that the elderly cancers were frequent in Togo, locating mostly in uterus cervix and breast in female, and prostate in men. This study could help to advocate the establishment of a cancer registry in Togo.
\end{abstract}

\section{Keywords}

Cancer, Elderly, Togo

\footnotetext{
${ }^{*}$ Corresponding author.
}

How to cite this paper: Darré, T., Walla, A., Kpatcha, T.M., Aboubakari, A.-S., Maneh, N., Koulinga, M., Amégbor, K. and Koura, G.N. (2016) Cancers in the Elderly Seen in Anatomical Pathology Laboratory in Lomé, Togo. Open Journal of Pathology, 5, 26-31. http://dx.doi.org/10.4236/ojpathology.2016.61005 


\section{Introduction}

Cancers are a real public health issue. They affect individuals of all ages, but the risk of occurrence and related deaths to cancer rise sharply with age [1]. In Western countries, the significant increase in the population of elderly leads to a raise of the incidence of cancer [1] [2]. The duration of carcinogenesis, greater tissue sensitivity to carcinogens and the effects of aging contribute to the development of cancers in older adults [3] [4]. In Africa, where emerging non-communicable diseases, chronic diseases such as hypertension and diabetes, studies addressing cancer in the elderly seem few mainly because of the non availability of effective tools for data collection including cancer registries [5] [6].

The purpose of this study was to describe the epidemiological and histological aspects of cancer among subjects aged 65 and over in Togo. These data could help to strengthen advocacy for the establishment of a registry of cancer.

\section{Materials and Methods}

We conducted a retrospective and descriptive study of all cases of cancer among subjects aged 65years and older diagnosed between January 1995 and December 2014 (20 years) in the laboratory of pathology of the university teaching hospital of Lomé. These cases were collected from the records of that laboratory. The samples examination techniques consisted primarily of paraffin embedded $\left(56^{\circ} \mathrm{C}-60^{\circ} \mathrm{C}\right)$ and then stained with hematoxylin eosin. The variables studied were epidemiological (gender, age, origin) and histological data (seat, histological type).

\section{Statistical Analysis}

Categorical variables are expressed as counts and percentages and continuous variables are expressed as means and standard deviations (SDs). The processing and data analysis were performed using Epi Info version 3.5.1.

\section{Ethical Considerations}

The confidentiality of data banks has been respected according to the ethical rules in force in Togo. This studyreceived approval from theHead of the laboratory department tobe conducted. Since it was counting records, patient consent was not required. However during the countingand data collection patient names were notcollectedin order to preserveconfidentiality.

\section{Results}

\subsection{Epidemiology}

We collected during our study period 792 cases of elderly cancer representing 15.2\% (5200 cases) of all cancers diagnosed in the Laboratory. The annual incidence was 39.6 cases. We observed 454 cases (57.3\%) of males and 338 cases $(42.7 \%)$ of male subject about a sex ratio (M/F) of 1.3. Patient age ranged from 65 to 103 years old, with a mean of $68.5 \pm 4$ years old. Among males, the mean age was $66.4 \pm 9$ years old and mean age was $71.2 \pm$ 3 years old among females. The topographic distribution showed that these cancers preferentially sit in humans to the prostate $(\mathrm{n}=171$ cases; $38 \%)$ and stomach $(\mathrm{n}=55$ cases; $12.1 \%)$; in women the cervix $(\mathrm{n}=55$ cases; 16.2\%) and breast $(\mathrm{n}=54$ cases; $15.8 \%)$ were the most represented sits (Table 1$)$.

\subsection{Histology}

The studied samples were 502 cases (63.4\%) of biopsies and 290 cases (36.6\%) of surgical specimens. The overall distribution of elderly cancer noted four histological groups: carcinomas ( $\mathrm{n}=706$ cases; 89.1\%), sarcomas $(n=43$ cases; $5.5 \%)$, lymphoma $(n=34$ cases; $4.3 \%)$ and melanoma ( $n=9$ cases; $1.1 \%)$. Cancers were at a localized stage in 11 cases, all of which 7 carcinoma in situ localized in the breast and 4 in the cervix. Carcinomas were observed at a mean age of 67.4 years, distributed in 397 cases (56.2\%) of males and 309 cases (43.8\%) of female. The histological types are shown in Table 2. We noticed a predominance of adenocarcinoma ( $\mathrm{n}=354$ cases; $44.6 \%$ ) followed by squamous cell carcinoma ( $n=239$ cases; $30.2 \%$ ).

Sarcomas in the elderly were observed at a mean age of 73.6 years old, distributed in 24 cases (55.8\%) in men and 19 cases in women (44.2\%). These sarcomas sat in the skin ( $\mathrm{n}=35 \mathrm{cases} ; 81.4 \%$ ), digestive tract ( $\mathrm{n}=5$ cases; 
Table 1. Distribution of elderly cancer by site and sex.

\begin{tabular}{|c|c|c|c|c|c|c|}
\hline \multirow[b]{2}{*}{ Seats } & \multicolumn{2}{|c|}{ Male } & \multicolumn{2}{|c|}{ Female } & \multicolumn{2}{|c|}{ Male + Female } \\
\hline & Number & $\%$ & Number & $\%$ & Number & $\%$ \\
\hline Lips & 2 & 0.44 & 1 & 0.30 & 3 & 0.38 \\
\hline Language & 7 & 1.55 & 2 & 0.59 & 9 & 1.14 \\
\hline Mouth & 4 & 0.88 & 2 & 0.59 & 6 & 0.76 \\
\hline Salivary Gland & 3 & 0.66 & 1 & 0.30 & 4 & 0.51 \\
\hline Pharynx & 7 & 1.55 & 3 & 0.89 & 10 & 1.26 \\
\hline Esophagus & 30 & 6.61 & 6 & 1.78 & 36 & 4.55 \\
\hline Stomach & 55 & 12.11 & 31 & 9.17 & 86 & 10.86 \\
\hline Small intestine and colon & 10 & 2.20 & 9 & 2.66 & 19 & 2.40 \\
\hline Rectum and anal canal & 20 & 4.40 & 14 & 4.14 & 34 & 4.29 \\
\hline Liver and biliary & 1 & 0.22 & 5 & 1.48 & 6 & 0.76 \\
\hline Pancréas & 3 & 0.66 & 1 & 0.30 & 4 & 0.51 \\
\hline Nasal et sinus Fosse & 4 & 0.88 & 6 & 1.78 & 10 & 1.26 \\
\hline Larynx & 9 & 1.98 & 7 & 2.07 & 15 & 1.89 \\
\hline Trachea, bronche, lungs & 10 & 2.20 & 8 & 2.37 & 18 & 2.27 \\
\hline Bone and cartilage & 14 & 3.08 & 11 & 3.25 & 25 & 3.16 \\
\hline Skin & 20 & 4.41 & 19 & 5.62 & 39 & 4.93 \\
\hline Soft tissue & 25 & 5.51 & 25 & 7.40 & 50 & 6.31 \\
\hline Breast & 6 & 1.32 & 54 & 15.98 & 60 & 7.58 \\
\hline Vulva & - & - & 3 & 0.89 & 3 & 0.38 \\
\hline Vagina & - & - & 2 & 0.59 & 2 & 0.22 \\
\hline Cervix & - & - & 55 & 16.27 & 55 & 6.94 \\
\hline Utérine body & - & - & 32 & 9.47 & 32 & 4.04 \\
\hline Ovary & - & - & 2 & 0.59 & 2 & 0.25 \\
\hline Prostate & 171 & 37.67 & - & - & 171 & 21.59 \\
\hline Kidney & 1 & 0.22 & 3 & 0.89 & 4 & 0.51 \\
\hline Bladder & 6 & 1.32 & 4 & 1.18 & 10 & 1.26 \\
\hline Eye & 1 & 0.22 & 5 & 1.48 & 6 & 0.76 \\
\hline Thyroid & 1 & 0.22 & 1 & 0.30 & 2 & 0.25 \\
\hline Unclear Seat & 9 & 1.98 & 13 & 3.85 & 22 & 2.78 \\
\hline Lymphoid tissue & 25 & 5.51 & 23 & 6.80 & 48 & 6.06 \\
\hline All seats & 454 & 100 & 338 & 100 & 792 & 100 \\
\hline
\end{tabular}

$11.6 \%)$ and breast ( $n=3$ cases; 7\%). The histological types were dominated by Kaposi's sarcoma ( $n=14$ cases; $1.8 \%$ ) and dermatofibrosarcoma ( $\mathrm{n}=10$ cases; $1.3 \%$ ) (Table 2 ).

Hodgkin lymphomas (HL) were seen in 4 cases and non-Hodgkin in 30 cases. Non-Hodgkin lymphoma (NHL) was dominated by diffuse large B-cell lymphomas ( $\mathrm{n}=22$ cases; 73.33\%). Other lymphomas consisted of Malta lymphoma ( $n=6$ cases; 20\%) and T-cell lymphoma ( $=2$ cases; 6.67\%). The cases of HL were all classic 
Table 2. Distribution of elderly cancer according to histological types and groups.

\begin{tabular}{|c|c|c|}
\hline Histological types & Number of cases (n) & Percentage (\%) \\
\hline \multicolumn{3}{|c|}{ Carcinomas $(\mathrm{n}=706)$} \\
\hline Adénocarcinoma & 354 & 44.70 \\
\hline Squamous cell carcinoma & 239 & 30.18 \\
\hline Infiltrating ductal carcinoma & 59 & 7.45 \\
\hline Adenoid cystic carcinoma & 11 & 1.39 \\
\hline Mucinous carcinoma & 9 & 1.14 \\
\hline Papillary carcinoma & 7 & 0.88 \\
\hline Transitional cell carcinoma & 6 & 0.76 \\
\hline Clear cell carcinoma & 3 & 0.38 \\
\hline Undifferentiated carcinoma & 2 & 0.25 \\
\hline \multicolumn{3}{|c|}{ Sarcomas $(n=43)$} \\
\hline Kaposi sarcoma & 14 & 1.77 \\
\hline Dermatofibrosarcoma & 10 & 1.26 \\
\hline Fibrosarcoma & 8 & 1.01 \\
\hline Rhabdomyosarcoma & 5 & 0.63 \\
\hline Leiomyosarcoma & 3 & 0.38 \\
\hline Liposarcoma & 3 & 0.38 \\
\hline \multicolumn{3}{|c|}{ Lymphomas $(\mathrm{n}=34)$} \\
\hline LNH & 30 & 3.79 \\
\hline $\mathrm{LH}$ & 4 & 0.51 \\
\hline Melanomas & 9 & 1.14 \\
\hline All of cases & 792 & 100 \\
\hline
\end{tabular}

shape (3 nodular sclerosis form and 1 form of lymphocyte depletion).

Nine cases of melanoma were observed of which 8 were located in the lower limbs and 1 in the upper limbs; these melanoma were all observed in 5 men.

\section{Discussion}

\subsection{Epidemiology}

The rates of elderly cancer present significant variations through the world. Indeed, data found in northern countries with high technical platform and cancer registries are hardly comparable to those observed in Southern countries in which cancer registry is not available. The continuous and comprehensive record of all cases of cancer (cancer registry) is a guarantor of the quality of data and allows an approach to estimate the impact and the different epidemiological settings [2] [3].

Thus, in our study, the elderly cancers represented $15.2 \%$ of all cancers, comparable to the rate reported in Congo-Nkoua M'Bon which was $17.4 \%$, but very low compared to rates observed in Europe (60\%) and USA (65\%) [7] [8]. Cancers of the elderly were observed in both sexes with a slight male predominance; Nkoua M'Bon had reported a female predominance (63.1\%) [7]. In the United States, cancer of the elderly occurred in the proportions of $54 \%$ in men and $46 \%$ in women [9].

The average age of patients in our study is similar to those of African authors where seniors account for only 
$5 \%-10 \%$ of the whole population [7]. In Western countries, the population projections for the next fifty years predict an increase in the number of cancers associated with aging [3] [10]. It appears in our study topographical distribution identical to that of Nkoua M'Bon in Congo [7]. Indeed, in older men, prostate cancer is predominant while cervical and breast cancers are prevalent in elderly women. In France and the United States, the four most common cancers in the population aged 65 years and over are prostate cancer in men with an average age of 69 years, cervical and breast cancer in women at an average age of 66 years, and colorectal cancers and bronchopulmonary in both sexes [1] [3].

\subsection{Histology}

Carcinomas were the most frequent histological group in our study, dominated by prostatic adenocarcinoma and digestive localizations. The predominant histological type was invasive ductal carcinoma, and in squamous cell carcinoma in the cervix. Indeed, if there is evidence of reduced mortality factors for breast cancer, colorectal cancer and cervical cancer through screening in the population under 65, few studies have included people of 70 and over [2] [11]. The main goal of the screening is to reduce mortality by the diagnosis and treatment at an early stage of the disease [11].

Sarcomas represented the second histological group of elderly cancer, dominated by Kaposi's sarcoma. It is endemic in Africa with variable rates between 4 and 38\% versus rates below 1\% in Asia and Europe [12] [13]. In black Africa, with the advent of HIV infection, the incidence of Kaposi's sarcoma has increased in all countries [12]. The dermatofibrosarcoma are relatively common, with no apparent predisposing cause and are seen in both gender. These cancers have no epidemiological particularity in Africa [12]. Lymphomas occupied the third place among cancers in the elderly. They were mostly non-Hodgkin lymphomas in our study. In France, the increase in life expectancy now estimated at 77 years for men and 84 years for women, foreshadows a steady increase in the coming years in the incidence of NHL in the elderly [14]. It can be estimated that about one third of the new NHL diagnoses are worn today in subjects over 65 years [15]. Lymphomas diffuse large B cells were the most common in our study; they comprise $30 \%$ to $40 \%$ of the lymphoma in developed countries. [16] The age of the patient has been recognized as a key prognostic factor, being among those of the International Prognostic Index of the most discriminating aggressive lymphomas for the long-term survival (41\% survival at 5 years for subjects over 60 years versus $60 \%$ for the youngest) [16].

Melanomas in the elderly were uncommon in our study (1.14\%), confirming the trend that it is a rare disease in the black race. In South Africa, its rates vary between 0.5 and 1.8 cases per year per 100,000 population among black Africans against 4.4 to 6.2 per 100,000 per year in whites people [17]. It has been shown that advancing age is a pejorative factor independent of other prognostic factors for melanoma usually accepted [18]. It is however unclear whether this fact is due to a particular biological behavior of melanoma that develop in the aged individual with reduced immune defenses of the host, or both [17]. Although in some European studies there was a slight female predominance, all recent studies worldwide have shown a tendency to equality of its rate in both genders [19].

\section{Conclusion}

The elderly cancers are frequent in our country, in spite of the quality of data available because of lack of cancer registry. Prostate cancer in men, cervical and breast cancers in women were the most common cancer in the elderly. This study also allowed us to have knowledge on different histological types of elderly cancer dominated by adenocarcinomas. In light of this work, we advocate the installation of a cancer registry and the establishment of a free cancer care in the elderly.

\section{Conflicts of Interest}

The authors reported no conflict of interest.

\section{Authors Contributions}

TD: supervised for the design of the study, undertook the field study, performed data collection, analysis and interpretation of the results, and wrote the manuscript. AW, TMK, ASA, NM, and MK participated in the design of the study, supervised the data collection and participated in the data analysis. KA and NG were respon- 
sible for the overall scientific management of the study, the analysis and interpretation, and preparation of the final manuscript. All authors have read and approved the final manuscript to be submitted for publication

\section{References}

[1] Gonsalves, W. and Ganti, A.K. (2011) Targeted Anti-Cancer Therapy in the Elderly. Critical Reviews in Oncology/ Hematology, 78, 227-242. http://dx.doi.org/10.1016/j.critrevonc.2010.06.001

[2] Balducci, L. and Extermann, M. (2001) A Practical Approach to the Older Patients with Cancer. Current Problems in Cancer, 25, 7-76. http://dx.doi.org/10.1053/cn.2001.v25.111579

[3] Franceschi, S. and La Vecchia, C. (2001) Cancer Epidemiology in the Elderly. Critical Reviews in Oncology/Hematology, 39, 219-226. http://dx.doi.org/10.1016/S1040-8428(01)00102-0

[4] Micheli, A., Mugno, E., Krogh, V., Quinn, M.J., Coleman, M., Hakulinen, T., et al. (2002) Cancer Prevalence in European Registry Areas. Annals of Oncology, 13, 840-865. http://dx.doi.org/10.1093/annonc/mdf127

[5] Verdier, F. and Fourcade, L. (2007) Evolution of Cardiovascular Risk Factors in Developing Countries. Trop Med, 67, 552-558.

[6] Droz, J.P., Dunet Rodde, M.H. and Vitoux, A. (2008) Development of Geriatric Oncology: National and International Policy Aspects. Bulletin du Cancer, 95, 104-107.

[7] Nkoua M’Bon, J.B., Nsondé Malanda, J. and Moukassa, D. (2011) Cancers in the Elderly in Brazzaville. Carcinol Clin Afrique, 10, 43-46.

[8] Hill, C. and Doyon, F. (2008) The Incidence of Cancer in the Elderly. Bulletin du Cancer, 95, 7-10

[9] Edwards, B.K., Howe, H.L., Ries, L.A., Thun, M.J., Rosenberg, H.M., Yancik, R., et al. (2002) Annual Report to the Nation on the Status of Cancer, 1973-1999, Featuring Implications of Age and Aging on U.S. Cancer Burden. Cancer, 94, 2766-2792. http://dx.doi.org/10.1002/cncr.10593

[10] Repetto, L. and Balducci, L. (2002) A Case for Geriatric Oncology. The Lancet Oncology, 3, 289-297. http://dx.doi.org/10.1016/S1470-2045(02)00730-1

[11] Walter, L.C., Lewis, C.L. and Barton, M.B. (2005) Screening for Colorectal, Breast, and Cervical Cancer in the Elderly: A Review of the Evidence. American Journal of Medicine, 118, 1078-1086. http://dx.doi.org/10.1016/j.amjmed.2005.01.063

[12] Friedman-Kein, A.E. and Salteman, B. (1990) Clinical Manifestations of Classical, Endemic African, and Epidemic AIDS-Associated Kaposi’s Sarcoma. Journal of the American Academy of Dermatology, 22, 1237-1250. http://dx.doi.org/10.1016/0190-9622(90)70169-I

[13] Terret, C. (2008) Geriatric Oncology: Patient Assessment-Old with Cancer. Bulletin du Cancer, 95, 16-20

[14] Thieblemont, C. and Coiffier, B. (2007) Lymphoma in Older Patients. Journal of Clinical Oncology, 25, 1916-1923. http://dx.doi.org/10.1200/JCO.2006.10.5957

[15] Swenson, W.T., Wooldridge, J.E., Lynch, C.F., Forman-Hoffman, V.L., Chrischilles, E. and Link, B.K. (2005) Improved Survival of Follicular Lymphoma Patients in the United States. Journal of Clinical Oncology, 23, 5019-5026. http://dx.doi.org/10.1200/JCO.2005.04.503

[16] Engert, A., Ballova, V., Haverkamp, H., Pfistner, B., Josting, A., Dühmke, E., et al. (2005) Hodgkin’s Lymphoma in Elderly Patients: A Comprehensive Retrospective Analysis from the German Hodgkin's Study Group. Journal of Clinical Oncology, 23, 5052-5060. http://dx.doi.org/10.1200/JCO.2005.11.080

[17] Seidler, A.M., Pennie, M.L., Veledar, E., Culler, S.D. and Chen, S.C. (2010) Economic Burden of Melanoma in the Elderly Population. JAMA Dermatology, 146, 249-256. http://dx.doi.org/10.1001/archdermatol.2009.389

[18] Swetter, S.M., Boldrick, J.C., Jung, S.Y., Egbert, B.M. and Harvell, J.D. (2005) Increasing Incidence of Lentigo Maligna Melanoma Subtypes: Northern California and National Trends from 1990 to 2000. Journal of Investigative Dermatology, 125, 685-691. http://dx.doi.org/10.1111/j.0022-202X.2005.23852.X

[19] Nagore, E., Hueso, L., Botella-Estrada, R., Alfaro-Rubio, A., Serna, I., Guallar, J., et al. (2010) Smoking, Sun Exposure, Number of Nevi and Previous Neoplasias Are Factoring Risk for Melanoma in Older Patients (60 Years and over). Journal of the European Academy of Dermatology and Venereology, 24, 50-57. http://dx.doi.org/10.1111/j.1468-3083.2009.03353.x 